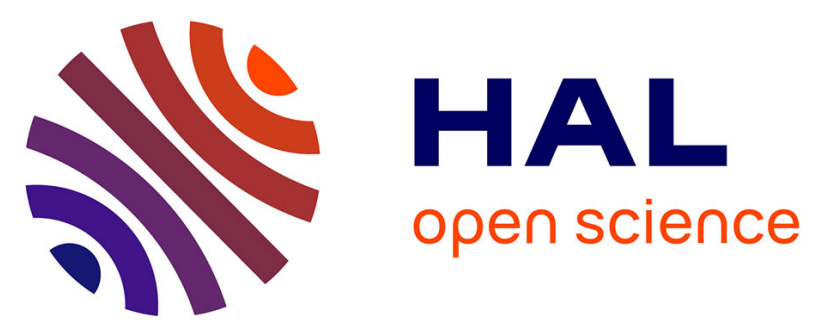

\title{
One-pot syntheses of heterotelechelic $\alpha$-vinyl, $\omega$-methoxysilane polyethylenes and condensation into comb-like and star-like polymers with high chain end functionality
}

Douriya Khedaioui, Benjamin Burcher, David Gajan, Damien Montarnal, Franck d'Agosto, Christophe Boisson

\section{To cite this version:}

Douriya Khedaioui, Benjamin Burcher, David Gajan, Damien Montarnal, Franck d'Agosto, et al.. One-pot syntheses of heterotelechelic $\alpha$-vinyl, $\omega$-methoxysilane polyethylenes and condensation into comb-like and star-like polymers with high chain end functionality. Polymer Chemistry, 2020, 11 (23), pp.3884-3891. 10.1039/d0py00638f . hal-02972738

\author{
HAL Id: hal-02972738 \\ https://hal.science/hal-02972738
}

Submitted on 12 Nov 2020

HAL is a multi-disciplinary open access archive for the deposit and dissemination of scientific research documents, whether they are published or not. The documents may come from teaching and research institutions in France or abroad, or from public or private research centers.
L'archive ouverte pluridisciplinaire HAL, est destinée au dépôt et à la diffusion de documents scientifiques de niveau recherche, publiés ou non, émanant des établissements d'enseignement et de recherche français ou étrangers, des laboratoires publics ou privés. 


\section{ARTICLE}

\section{One-pot syntheses of heterotelechelic $\alpha$-vinyl, $\omega$-methoxysilane polyethylenes and condensation into comb-like and star-like polymers with high chain end functionality.}

Received 00th January 20xx, Accepted 00th January 20xx DOI: $10.1039 / x 0 \times x 00000 x$

\author{
Douriya Khedaioui, ${ }^{a}$ Benjamin Burcher, ${ }^{a}$ David Gajan, ${ }^{b}$ Damien Montarnal, ${ }^{* a}$ Franck D’Agosto*a \\ and Christophe Boisson* ${ }^{\mathrm{a}}$
}

\begin{abstract}
A one-pot synthesis method for various $\alpha$-vinyl, $\omega$-methoxysilyl polyethylene oligomers with well-defined lengths and high end-group functionalities and crystallinities is presented. This method relies on the combination of catalyzed chain growth of ethylene in the presence of a di(alkenyl)magnesium chain transfer agent and a neodymocene complex, followed by efficient deactivation using a variety of silane reagents: trimethoxymethylsilane, trimethoxyvinylsilane and tetramethoxysilane. Further condensation of the $\omega$ methoxysilyl groups of these polymers in active medium (toluene/acetic acid mixture) leads to complex architectures such as comb-like structures or star-like structures that combine high vinyl functionality at extremities

with

a

high

crystallinity.
\end{abstract}

\section{Introduction}

Polymers containing alkoxysilyl reactive groups $\left(-\mathrm{Si}(\mathrm{OR})_{\mathrm{x}}, \mathrm{x}=1\right.$ to 3$)$ also called silyl-modified polymers (SMPs) have found numerous industrial applications over the years such as adhesives, coatings, sealants or elastomers. ${ }^{1-3}$ Reactions with moisture at room temperature afford a convenient way to enable latent cross-linking, and circumvents the use of solvents and toxic / sensitizing functional groups such as isocyanates. SMPs with the highest relevance for industrial applications are typically carrying the alkoxysilyl groups at chain ends ( $\alpha$-alkoxysilyl end-capped polymers or $\alpha, \omega$-di(alkoxysilyl) telechelic polymers $\left(-\mathrm{Si}(\mathrm{OR})_{x}, \mathrm{x}=1\right.$ to 3$)$ ). Two main strategies are used to synthesize such polymers: the introduction of the alkoxysilyl functional group can be performed (i) during the polymerization process via the use of alkoxysilylfunctional initiators, chain transfer agents or terminating agents or (ii) by the post-functionalization of a telechelic polymer. A comprehensive review ${ }^{4}$ by Guillaume illustrates that these two strategies enable the synthesis of a very large variety of SMPs. The first strategy (i) afforded cycloalkenamers by acyclic diene metathesis (ADMET) or ring opening metathesis polymerization (ROMP), ${ }^{5-7}$ polyisoprene or polyisoprene-based triblock copolymers, $^{8-11}$ polybutadiene, ${ }^{12}$ polystyrene and their block

\footnotetext{
Univ Lyon, Université Claude Bernard Lyon 1, CPE Lyon, CNRS, UMR 5265 Chemistry, Catalysis, Polymers and Processes 43 Bvd du 11 Novembre 1918, 69616 Villeurbanne (France).

${ }^{b .}$ Institut des Sciences Analytiques UMR 5280 (CNRS/Université Lyon1/ENS Lyon), Université Lyon, Centre de RMN à Très Hauts Champs, 69100 Villeurbanne, France Electronic Supplementary Information (ESI) available: ${ }^{1} \mathrm{H},{ }^{13} \mathrm{C},{ }^{1} \mathrm{H}-{ }^{13} \mathrm{C}-\mathrm{HSQC}$ and MALDI-TOF analyses, and Mark-Houwink plots. See DOI: 10.1039/x0xx00000x
}

copolymers. ${ }^{13,14}$ The second strategy is more versatile and leads to SMP based on polylactides, ${ }^{15}$ polythiophenes, ${ }^{16,17}$ polybutadiene, ${ }^{18-}$ 21 hydrogenated polybutadiene, ${ }^{22,23}$ polydimethylsiloxane, ${ }^{23}$ polycaprolactone (and polycaprolactone/polydimethylsiloxane blend), ${ }^{24,25}$ poly (n-butyl acrylate), ${ }^{26}$ polyaziridine, ${ }^{27}$ poly(ethylene glycol) and poly(propylene glycol) and their copolymers. ${ }^{22,26,28-31}$ Among this variety of SMPs, and despite the industrial importance of polyethylene (PE), examples of $\mathrm{PE}$ end-functionalized with alkoxysilyl groups remain scarce. Zhang et al. and Peng et al. showed that $\mathrm{Si}\left(\mathrm{CH}_{3}\right)_{x}\left(\mathrm{OCH}_{3}\right)_{3-\mathrm{x}}-\mathrm{PE}(\mathrm{x}=0$ or 1 ) could be successfully obtained through a multi-step process and after Soxhlet extractions to obtain well-defined $\omega$-vinyl-polyethylene followed by a thiol-ene post-functionalization with dimethoxysilane or trimethoxysilane reagents. ${ }^{32-34}$ They also investigate the hydrolysis-condensation of the $\omega$-methoxyysilyl group to obtain sophisticated architectures. As a matter of fact, Ye et al. have nicely described performance properties of functional complex polyethylene architectures notably for building blocks or encapsulation applications. ${ }^{35,36}$ We recently showed that telechelic PEs carrying a variety of functional end groups could be produced using catalyzed polyethylene chain growth (CCG) also known as Coordinative Chain-Transfer Polymerization (CCTP) through the combination of a neodymocene complex $\left[\left(\mathrm{C}_{5} \mathrm{Me}_{5}\right)_{2} \mathrm{NdCl}_{2} \mathrm{Li}\left(\mathrm{OEt}_{2}\right)_{2}\right]$ and a functionalized chain transfer agent. ${ }^{37,38}$ Using the di(10-undecenyl)magnesium (Scheme 1) as chain transfer agent, ${ }^{37}$ well-defined $\mathrm{CH}_{2}=\mathrm{CH}-\mathrm{PE}-\mathrm{Mg}-\mathrm{PE}-\mathrm{CH}=\mathrm{CH}_{2}$ are formed in situ and can be deactivated with suitable functional reagents to yield heterotelechelic $\alpha$-vinyl, $\omega$-functional PEs (Vin-PE$\mathrm{Z}$, with $\mathrm{Z}=-\mathrm{I},-\mathrm{SC}(=\mathrm{S}) \mathrm{NEt}_{2}$, or $\left.-\mathrm{SC}(=\mathrm{S}) \mathrm{OEt}\right)$. Further modification of the $\alpha$ - or $\omega$ - groups using thiol-ene reaction and nucleophilic substitutions, respectively, affords a very large extent of 
modification. ${ }^{39-42}$ Homobifunctional $\mathrm{Si}\left(\mathrm{OCH}_{3}\right)_{3}-\mathrm{PE}-\mathrm{Si}\left(\mathrm{OCH}_{3}\right)_{3} \mathrm{SMPs}$ could be obtained in this way by thiol-ene coupling between an $\alpha, \omega$-divinyl PE and (3-mercaptopropyl)trimethoxysilane. ${ }^{43}$

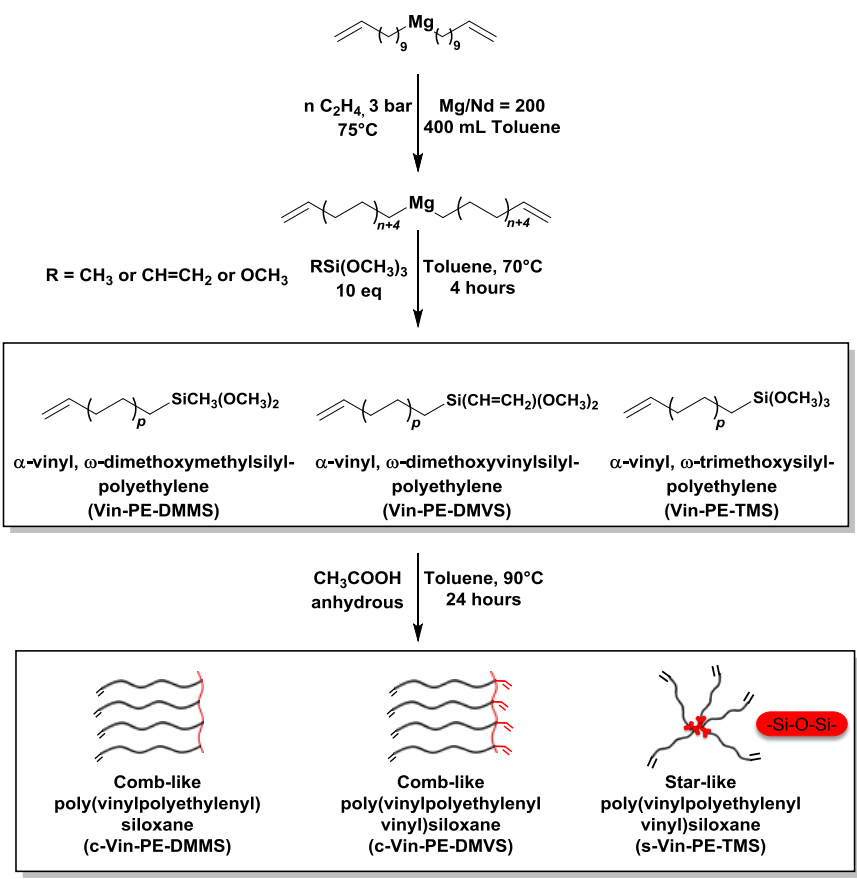

Scheme 1. Synthesis of vinyl functionalized PE using CCG polymerization of ethylene, followed by a post condensation of alkoxysilyl end chains.

In the present work, we investigate a straightforward and atomeconomic strategy to obtain heterobifunctional telechelic SMPs based on PE by direct deactivation of $\alpha$-vinyl growing polymer chains using methoxysilane reagents (Scheme 1). We illustrate the versatility of this strategy with different silanes such as trimethoxymethylsilane (TMMS), trimethoxyvinylsilane (TMVS) and tetramethoxysilane (TMOS) that lead to a variety of $\alpha$-vinyl, $\omega$ functional $\quad \mathrm{PE}: \quad \mathrm{CH}_{2}=\mathrm{CH}-\mathrm{PE}-\mathrm{SiCH}_{3}\left(\mathrm{OCH}_{3}\right)_{2}, \quad \mathrm{CH}_{2}=\mathrm{CH}-\mathrm{PE}-$ $\mathrm{Si}\left(\mathrm{CH}=\mathrm{CH}_{2}\right)\left(\mathrm{OCH}_{3}\right)_{2}$ and $\mathrm{CH}_{2}=\mathrm{CH}-\mathrm{PE}-\mathrm{Si}\left(\mathrm{O} \mathrm{CH}_{3}\right)_{3}$, respectively. The $\omega$ methoxysilyl groups can be further involved in an intermolecular condensation process to form Si-O-Si bonds, leading to a variety of branched architectures such as comb-like polysiloxanes with $\alpha$ vinyl, polyethylene side chains from $\mathrm{CH}_{2}=\mathrm{CH}-\mathrm{PE}-\mathrm{SiCH}_{3}\left(\mathrm{OCH}_{3}\right)_{2}$ and $\mathrm{CH}_{2}=\mathrm{CH}-\mathrm{PE}-\mathrm{Si}\left(\mathrm{CH}=\mathrm{CH}_{2}\right)\left(\mathrm{OCH}_{3}\right)_{2}$, or star-like polymers made of a polysiloxane core surrounded by $\alpha$-vinyl, polyethylene arms with $\mathrm{CH}_{2}=\mathrm{CH}-\mathrm{PE}-\mathrm{Si}\left(\mathrm{OCH}_{3}\right)_{3}$.

While condensation of alkoxysilanes is typically carried out through hydrolysis and condensation steps, often involving catalysts such as organotin derivatives, ${ }^{44}$ we opted for a process that combines an excess of acetic acid and apolar solvents (active medium) ${ }^{45,46}$ to circumvent the use of toxic compounds. During this process, acetic acid acts both as a substituent that can be exchanged with alkoxides on the Si center and as an esterification reagent with alcohols that enables in situ the formation of water. Hydrolysis and condensation steps in such conditions can be carried out without additional catalysts.

\section{Experimental section}

\section{Materials}

Di(10-undecenyl)magnesium was synthesized according to the literature $\left(0.34 \mathrm{~mol} \mathrm{~L}^{-1}\right) .{ }^{37} n$-butyl- $n$-octylmagnesium (BOMAG, 0.88 $\mathrm{mol} \mathrm{L}^{-1}$ ) in heptane was purchased from LANXESS Organometallics and $\left[\left(\mathrm{C}_{5} \mathrm{Me}_{5}\right)_{2} \mathrm{NdCl}_{2} \mathrm{Li}\left(\mathrm{OEt}_{2}\right)_{2}\right]$ was purchased from MCAT. Anhydrous di- $n$-butyl ether was purchased from Merck (99.3\%). The functionalizing agents such as trimethoxymethylsilane (TMMS, 98\%) tetramethoxysilane (TMOS, >99\%) and trimethoxyvinylsilane (TMVS, 98\%) were purchased from Merck and used without purification. Anhydrous acetic acid (AA, >99\%, Merck) and anhydrous methanol (99.8\%, Merck) were used as received. Toluene was distilled on sodium and stored under argon.

\section{Analytical Techniques}

High-resolution liquid NMR spectroscopy was carried out with a Bruker DRX 400 spectrometer operating at $400 \mathrm{MHz}$ for the ${ }^{1} \mathrm{H}$ nucleus, and $101 \mathrm{MHz}$ for ${ }^{13} \mathrm{C}$. Spectra were recorded at $363 \mathrm{~K}$ using a $5 \mathrm{~mm}$ QNP for ${ }^{1} \mathrm{H}$ NMR and a PSEX $10 \mathrm{~mm}$ probe for ${ }^{13} \mathrm{C}$ NMR and ${ }^{29} \mathrm{Si}$ NMR. A mixture of tetrachloroethylene (TCE) and deuterated benzene (TCE $/ \mathrm{C}_{6} \mathrm{D}_{6}$ 2:1 vol) was used as solvent. Chemical shift values are given in units of ppm, relative to $\mathrm{C}_{6} \mathrm{D}_{5} \mathrm{H}$ signal for ${ }^{1} \mathrm{H}$ NMR (7.16 ppm), to methylenes of the PE chain at $30.06 \mathrm{ppm}$ for ${ }^{13} \mathrm{C}$ NMR. $\quad{ }^{1} \mathrm{H}-{ }^{13} \mathrm{C}$ heteronuclear single quantum correlation spectroscopy (HSQC) spectrum was recorded at $363 \mathrm{~K}$ with 64 scans using a PSEX $10 \mathrm{~mm}$ probe.

${ }^{29} \mathrm{Si}$ solid-state NMR was performed on a Bruker DSX-300 spectrometer operating at $59.63 \mathrm{MHz}$ by use of cross-polarization from proton. The contact time was $5 \mathrm{~ms}$, the recycle delay $1 \mathrm{~s}$, and the spinning rate $10 \mathrm{kHz}$. Sodium trimethylsilylpropanesulfonate (DSS) was used as reference.

High temperature size exclusion chromatography (HT- SEC) analyses were performed using a triple detection Viscotek system from Malvern Instruments that incorporates a differential refractive 
index detector, a differential viscometer and a dual light-scattering detector (LALS and RALS). 1,2,4-trichlorobenzene (TCB), stabilized with 2,6-di(tert-butyl)-4-methylphenol (0.02 wt\%), was used as the

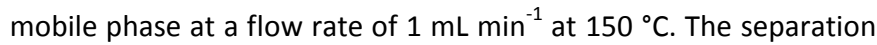
was carried out on three Agilent columns (PL gel Olexis $300 \times 7 \mathrm{~mm}$ ) and a guard column (PL gel $5 \mu \mathrm{m}$ ). The molar mass distribution was calculated using a conventional calibration from poly(ethylene) standards $\left(M_{\mathrm{p}}=380,507,770,1890,17000,27300,53100,65700\right.$, $66300,78400 \mathrm{~g} \mathrm{~mol}^{-1}$ ) from Polymer Standard Service (Mainz). The Mark-Houwink plots were constructed according to the universal calibration. Differential Scanning Calorimetry analyses were performed on a Mettler Toledo DSC-1 apparatus using sealed $40 \mu \mathrm{L}$ aluminum pans and 7-10 mg samples. Two heating/cooling cycles between $-40{ }^{\circ} \mathrm{C}$ and $180{ }^{\circ} \mathrm{C}$ at $10{ }^{\circ} \mathrm{C} \mathrm{min}^{-1}$ were performed. The degree of crystallinity and melting temperature of PEs were calculated from the second heating endotherm using the standard melting enthalpy of polyethylene: $293 \mathrm{~J} \mathrm{~g}^{-1}$.

Matrix-assisted laser desorption/ionization time of flight (MALDITOF) mass spectrometry analyses were recorded in the reflectron mode, cationized with a sodium salt, using an Applied Biosystems Voyager DE-STR. The samples were prepared by mixing a solution of polymer in toluene preheated at $70^{\circ} \mathrm{C}\left(1 \mathrm{~g} \mathrm{~L}^{-1}\right)$, and a solution of matrix (dithranol) in toluene $\left(10 \mathrm{~g} \mathrm{~L}^{-1}\right)$ with a volumetric ratio of 1:1. The resulting mixture $(1 \mu \mathrm{L})$ was placed on the sample plate and the toluene was evaporated at room temperature. The resulting spectra were compared with simulations performed with the IsoPro software.

\section{Syntheses of hetero-telechelic PEs: $\alpha$-vinyl, $\omega$ - dimethoxymethylsilyl PE (Vin-PE-DMMS), $\alpha$-vinyl, $\omega$ - dimethoxyvinylsilyl PE (Vin-PE-DMVS) and $\alpha$-vinyl, $\omega$ - trimethoxysilyl PE (Vin-PE-TMS)}

A solution of di(10-undecenyl) magnesium in di( $n$-butyl ether), ${ }^{37}$ and $\left[\left(\mathrm{C}_{5} \mathrm{Me}_{5}\right)_{2} \mathrm{NdCl}_{2} \mathrm{Li}\left(\mathrm{OEt}_{2}\right)_{2}\right](\mathrm{Mg} / \mathrm{Nd}=200)$ was diluted with $400 \mathrm{~mL}$ of toluene. The resulting solution was transferred to a reactor under an argon atmosphere. The reactor was heated to $75{ }^{\circ} \mathrm{C}$ and then connected to a ballast containing ethylene at a pressure of 3 bars. After the desired consumption of ethylene, the atmosphere of the reactor was vented and replaced with argon. Then, the alkoxysilane reagents (TMMS, TMOS or TMVS, 10 eq compared to $\mathrm{Mg}$ ) were transferred to the reactor at $70^{\circ} \mathrm{C}$. TMMS and TMVS were diluted in $10 \mathrm{~mL}$ of toluene whereas TMOS was transferred without any dilution. After 5 hours under stirring, the reaction mixture was collected and filtered under argon. After washing three times with $30 \mathrm{~mL}$ of anhydrous methanol, the precipitated polymer was dried under reduced pressure. Vin-PE-DMMS, Vin-PE-DMVS and Vin-PETMS were then isolated and stored in a glove box. Their characterizations by ${ }^{1} \mathrm{H}$ (Figure 1) and ${ }^{13} \mathrm{C}$ NMR (Figure S3, S4, S5) show signals at:

\section{Vin-PE-DMMS:}

${ }^{1} \mathrm{H}$ NMR (TCE $\left./ \mathrm{C}_{6} \mathrm{D}_{6} 2 / 1,400 \mathrm{MHz}, 363 \mathrm{~K}\right) \delta \mathrm{ppm}:-0.01(\mathrm{~s}), 0.55(\mathrm{t})$ $0.84(\mathrm{t}), 1.25(\mathrm{br}), 1.96(\mathrm{q}), 3.38(\mathrm{~s}), 4.84-4.93(\mathrm{~m}), 5.70(\mathrm{~m})$

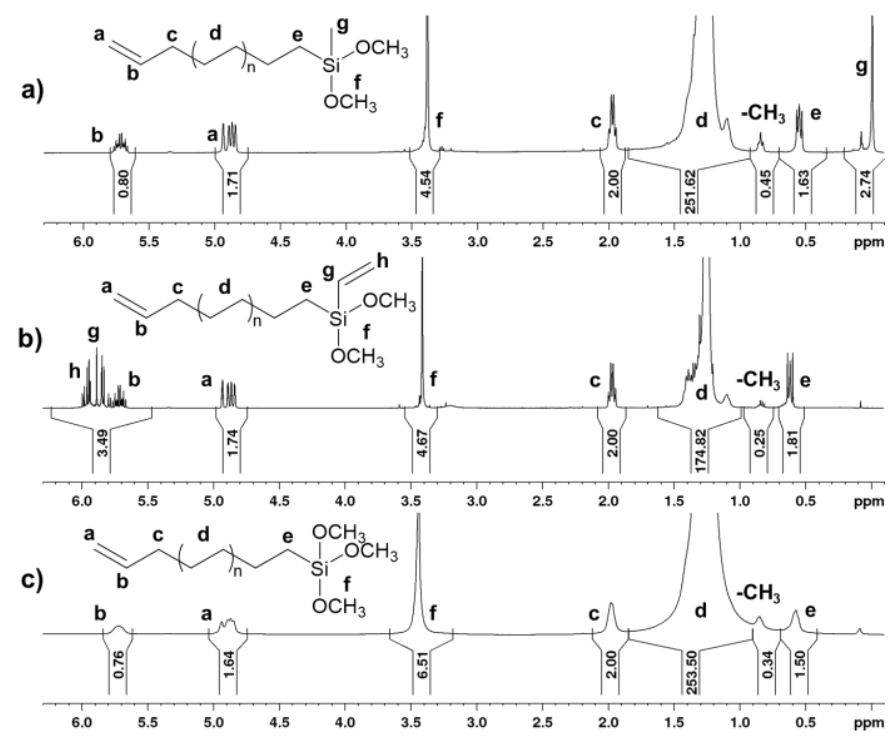

Figure 1. ${ }^{1} \mathrm{H}$ NMR spectra of a) Vin-PE-DMMS, b) Vin-PE-DMVS, c) Vin-PE-TMS

${ }^{13} \mathrm{C}$ NMR (TCE/C $\left.\mathrm{C}_{6} \mathrm{D}_{6} 2 / 1,100 \mathrm{MHz}, 363 \mathrm{~K}\right) \delta \mathrm{ppm}:-5.51,13.82,23.12$, 29.38, 29.50, 29.70, 29.8, 30.06, 33.49, 34.04, 49.80, 114.25, 138.9

\section{Vin-PE-DMVS}

${ }^{1} \mathrm{H}$ NMR (TCE $\left./ \mathrm{C}_{6} \mathrm{D}_{6} 2 / 1,400 \mathrm{MHz}, 363 \mathrm{~K}\right) \delta \mathrm{ppm}: 0.61(\mathrm{t}), 1.25(\mathrm{br})$, $1.96(\mathrm{q}), 3.41(\mathrm{~s}), 4.84-4.93(\mathrm{~m}), 5.70(\mathrm{~m})$, 5.78-6.00 (m)

${ }^{13} \mathrm{C}$ NMR $\left(\mathrm{TCE} / \mathrm{C}_{6} \mathrm{D}_{6} 2 / 1,100 \mathrm{MHz}, 363 \mathrm{~K}\right) \delta \mathrm{ppm}: 12.75$ 22.92, 29.38, $29.49,29.67,29.85,30.06,33.47,34.04,50.15,114.25,133.23$, $134.89,138.98$

Vin-PE-TMS:

${ }^{1} \mathrm{H}$ NMR (TCE/C $\left.{ }_{6} \mathrm{D}_{6} 2 / 1,400 \mathrm{MHz}, 363 \mathrm{~K}\right) \delta \mathrm{ppm}: 0.57(\mathrm{t}), 0.85(\mathrm{t})$, 1.25 (br), $1.96(\mathrm{q}), 3.44(\mathrm{~s}), 4.84-4.93(\mathrm{~m}), 5.70(\mathrm{~m})$

${ }^{13} \mathrm{C}$ NMR $\left(\mathrm{TCE} / \mathrm{C}_{6} \mathrm{D}_{6} 2 / 1,100 \mathrm{MHz}, 363 \mathrm{~K}\right) \delta \mathrm{ppm}: 9.86,23.04,29.38$, $29.49,29.66,29.85,30.06,33.31,34.03,50.15,114.25,138.98$

Syntheses of comb-like PE (comb-Vin-PE-DMMS and comb-Vin-PEDMVS) and star-like PE (star-Vin-PE-TMS) after condensation of methoxysilyl groups of corresponding hetero-telechelic PEs

Vin-PE-DMMS, Vin-PE-DMVS and Vin-PE-TMS were dissolved in toluene ( $10 \mathrm{wt} \%$ of polymer) at $90^{\circ} \mathrm{C}$ for 1 hour. Upon solubilization, dry acetic acid was added in different concentrations and the reaction was carried out during 24 hours at $90^{\circ} \mathrm{C}$. The resulting polymers, comb-Vin-PE-DMMS, comb-Vin-PE-DMVS and star-Vin PE-TMS, were filtered and washed three times with methanol.

\section{Results and discussion}

Previous developments on catalyzed polyethylene chain growth on magnesium have successfully taken advantage of the reactivity of di(polyethylenyl)magnesium compounds (R-PE-Mg-PE-R) with a suitable functionalizing agent to propose highly versatile platforms to produce many end-functional polyethylene chains. ${ }^{37}$ This technique offers a one-pot process to obtain highly functional telechelic polyethylene chains with well-defined molar masses. We thus took advantage of the availability of various alkoxysilane 
Table 1. Characterizations of Vin-PE-DMMS, Vin-PE-DMVS and Vin-PE-TMS and the corresponding condensed polyethylenes comb-Vin-PE-DMMS, comb-Vin-PE-DMVS and starVin-PE-TMS

derivatives in order to investigate for the first time their reaction with R-PE-Mg-PE-R.

Preliminary experiments targeting 4-arm PE structures by directly reacting TMOS with $\mathrm{PE}-\mathrm{Mg}-\mathrm{PE}(\mathrm{Si} / \mathrm{Mg}=0.5)$ were performed using $\left[\left(\mathrm{C}_{5} \mathrm{Me}_{5}\right)_{2} \mathrm{NdCl}_{2} \mathrm{Li}\left(\mathrm{OEt}_{2}\right)_{2}\right] /$ BOMAG catalytic system. However, NMR characterizations of the obtained product showed that the effective number of arms per Si center obtained in this way was mainly equal to 2 (Figure S1 and S2) as it was confirmed by the signal at 12.78 $\mathrm{ppm}$ in the ${ }^{13} \mathrm{C}$ NMR spectrum which is specific to the carbon adjacent to the silicon atom in $\mathrm{PE}_{2} \mathrm{Si}(\mathrm{OMe})_{2}$. In addition, a large distribution of structures including non-functionalized PE was obtained. This result could be explained by the difference of reactivity of the PE-Mg bond on the starting $\mathrm{Si}(\mathrm{OR})_{4}$ and on the forming $\mathrm{Si}(\mathrm{OR})_{4-x}(\mathrm{PE})_{x}$ species.

We took advantage of these first observations to direct our experiments toward the extension of the range of the $\omega$-end group by designing well-defined and highly functionalized $\omega-S R_{3-x}\left(O R^{\prime}\right)_{x}-P E$ chains by simple deactivation of the polymerization medium with excess of alkoxysilane compounds.

\section{Syntheses of $\alpha$-vinyl, $\omega$-methoxysilyl PE oligomers}

After 5 hours of reaction of $\mathbf{C H}_{2}=\mathbf{C H}-\mathrm{PE}-\mathrm{Mg}-\mathrm{PE}-\mathbf{C H}=\mathbf{C H}_{\mathbf{2}}$ with $\mathrm{TMMS}$, TMVS and TMOS, the corresponding polymers, Vin-PE-DMMS, VinPE-DMVS and Vin-PE-TMS, were recovered by precipitation, washing, filtration and drying. All steps were performed under argon to prevent any hydrolysis. The successful incorporation of the $\omega$-alkoxysilyl group was confirmed in all cases by ${ }^{1} \mathrm{H}$ NMR analysis (Figure 1), which shows a triplet (e) at $0.55,0.61$ and $0.57 \mathrm{ppm}$ corresponding to the methylene adjacent to the silicon atom and a singlet at $3.38,3.41$ and $3.44 \mathrm{ppm}$ corresponding to methoxysilyl groups of the formed Vin-PE-DMMS, Vin-PE-DMVS and Vin-PE-TMS, respectively. It is worth mentioning that a broadening of the signals is observed in the case of Vin-PE- TMS. This could be explained by an onset of hydrolysis/condensation reaction during the NMR analysis. Presence of a small fraction of methyl $\omega$-end groups (signal at $0.85 \mathrm{ppm}$ ) are unavoidable, and may result from (i) $\beta-\mathrm{H}$ elimination reactions occurring during the ethylene polymerization step, ${ }^{47}$ (ii) impurities in alkoxysilane moieties or (iii) of incomplete deactivation reactions. In all cases, these side reactions remain minor and $\omega$-functionalisation above $83 \%$ and up to $92 \%$ could be obtained (Table 1). Moreover, by exploiting the integration values of the resonance of $-\mathrm{C}_{2}-\mathrm{Si}$ - and $-\mathrm{Si}-\mathrm{OCH}_{3}$, we highlighted the good correspondence between the number of $\mathrm{PE}$ chains per silicon atom and the number of methoxysilyl groups (details are given in Table S1). Complementary ${ }^{13} \mathrm{C}$ NMR analyses confirmed that the targeted structures were successfully formed (Figure S3, S4, S5). In particular, the methylene in $\alpha$-position of the silicon atom were clearly identified at 13.82, 12.75, 9.85 ppm for Vin-PE-DMMS, VinPE-DMVS and Vin-PE-TMS, respectively.

Molar masses obtained from HT-SEC analyses are in line with expectations as shown in Table 1. Yet, a small fraction of higher molar masses is observed, that could be explained by a starting condensation of methoxysilyl groups occurring during the sample preparation at $150^{\circ} \mathrm{C}$. This was confirmed by increasing the solubilization duration in TCB at $150^{\circ} \mathrm{C}$ before SEC analysis from 15 $\min$ to $5 \mathrm{~h}$, which resulted in a significant increase of the high molar mass fraction (Figure S6 in Supporting Information). Unfunctionalized PE chains cannot be usually

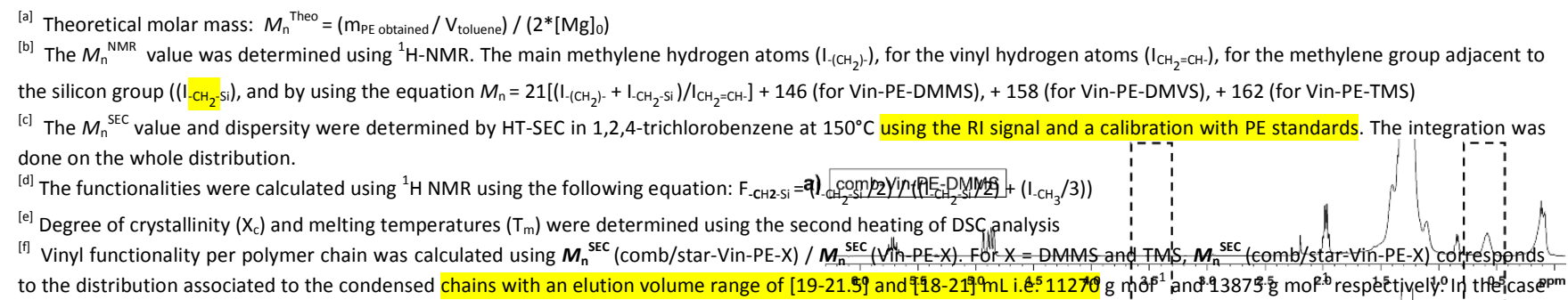
of X = DMVS, $\boldsymbol{M}_{\mathrm{n}}^{\text {SEC }}$ (comb-Vin-PE-DMVS) $=3740 \mathrm{~g} \mathrm{~mol}^{-1}$ 
analyzed by MALDI-ToF mass spectroscopy (MALDI-ToF MS) experiments but it was previously shown that the introduction of a alkoxysilyl functionalization ratio of about $83 \%$ determined above with ${ }^{1} \mathrm{H}$ NMR.

\begin{tabular}{|c|c|c|c|c|c|c|c|c|}
\hline Entry & Samples & $\begin{array}{l}M_{\mathrm{n}}^{\text {Theo [a] }} \\
\left(\mathrm{g} \mathrm{mol}^{-1}\right)\end{array}$ & $\begin{array}{l}M_{n}^{\text {NMR }[b]} \\
\left(\mathrm{g} \mathrm{mol}^{-1}\right)\end{array}$ & $\begin{array}{c}M_{\mathrm{n}}^{\mathrm{SEC}}(\Theta)^{[\mathrm{C}]} \\
\left(\mathrm{g} \mathrm{mol}^{-1}\right)\end{array}$ & $\mathrm{F}_{-\mathrm{CH}_{2}-\mathrm{Si}}{ }^{[\mathrm{d}]}$ & $\mathrm{X}_{\mathrm{c}}^{[\mathrm{e}]}(\%)$ & $\mathrm{T}_{\mathrm{m}}{ }^{[\mathrm{e}]}\left({ }^{\circ} \mathrm{C}\right)$ & 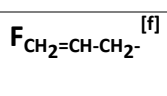 \\
\hline 1 & Vin-PE-DMMS & 1880 & 2276 & $2250(1.5)$ & $83 \%$ & 61 & 119 & 1 \\
\hline 2 & comb-Vin-PE-DMMS & - & - & $4900(1.7)$ & - & 50 & 120 & 5.0 \\
\hline 3 & Vin-PE-DMVS & 1330 & 1399 & $1640(1.9)$ & $92 \%$ & 58 & 114 & 1 \\
\hline 4 & comb-Vin-PE-DMVS & - & - & $3740(2.0)$ & - & 52 & 116 & 2.3 \\
\hline 5 & Vin-PE-TMS & 1730 & 2391 & $1850(1.7)$ & $87 \%$ & 67 & 121 & 1 \\
\hline 6 & star-Vin-PE-TMS & - & 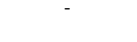 & $5150(2.7)$ & - & 62 & 123 & 7.5 \\
\hline
\end{tabular}

cationizable group allowed such analysis. ${ }^{37,38,48}$ MALDI-ToF MS analysis of Vin-PE-DMMS (Figure S7) revealed the presence of a single population $(m / z=146.05+28.03 n+23$, where $n$ is the number of ethylene units, 146.05 correspond to the exact molar mass of the $\alpha$ - and $\omega$-chain ends, i.e. $\mathrm{CH}_{2}=\mathrm{CH}_{-} \mathrm{CH}_{2}-$ and $\mathrm{Si}\left(\mathrm{CH}_{3}\right)\left(\mathrm{OCH}_{3}\right)_{2}$, and 23 the exact molar mass of sodium). One population was also identified for Vin-PE-DMVS (Figure $\mathrm{S} 8)(\mathrm{m} / \mathrm{z}=$ $158.08+28.03 n+23$ where 158.08 corresponds to the exact molar mass of the $\alpha$ - and $\omega$-chain ends, $\mathrm{CH}_{2}=\mathrm{CH}_{-}-\mathrm{CH}_{2}-$ and $-\mathrm{Si}$ $\left(\mathrm{CH}=\mathrm{CH}_{2}\right)\left(\mathrm{OCH}_{3}\right)_{2}$ respectively). In addition, the good match observed with the simulated isotopic distribution confirmed the successful synthesis of Vin-PE-DMMS and Vin-PE-DMVS. Eventually, as MALDI-TOF MS samples were prepared under air, rapid condensation of Vin-PE-TMS occurs and MALDI-ToF MS analysis turned out to be unsuccessful. In conclusion, the introduction of dimethoxymethylsilyl, dimethoxyvinylsilyl and trimethoxysilyl $\omega$-end groups on PE chains were successfully performed and fully characterized. The resulting polymers were further used as macromonomers for post-condensation reactions leading to original PE architectures.

\section{Post-condensation of $\alpha$-vinyl, $\omega$-methoxysilyl PEs into comb-like and star-like vinyl-functional polyethylenes}

The $\boldsymbol{\alpha}$-vinyl, $\boldsymbol{\omega}$-methoxysilyl PEs were further involved in a condensation reaction in the presence of an excess of acetic acid (AA) in toluene at $90^{\circ} \mathrm{C}$. This method was specifically chosen to ensure complete solubilization of PE macromonomers and good miscibility of all reagents. The process includes several steps: 1) methoxysilane acetoxylation producing methanol 2) esterification of the methanol producing water 3) acetoxysilane hydrolysis and 4) condensation of the products. The corresponding mechanism proposed by Egorova et al. is represented in Scheme S1. We first tried to identify the effect of an excess of AA on the condensation of Vin-PE-DMMS by conducting the reaction for 24 hours at $90{ }^{\circ} \mathrm{C}$ using 20 eq. and 40 eq of $A A$ with respect to methoxy groups (Figure S9). Using 20 eq. of AA both singlets of methoxysilyl groups at $3.38 \mathrm{ppm}$ are still visible, corresponding to a hydrolysis rate of $73 \%$. However, when using 40 eq. of AA this signal fully disappears, thus confirming the full acetoxylation and subsequent hydrolysis of the methoxysilyl groups. Moreover, the distribution of the molar masses in the two cases (Figure S9) also indicates a more complete conversion using 40 eq. of AA. The presence of a small polymer fraction with a molar mass similar to Vin-PE-DMMS corresponds to unfunctionalized $\alpha$-vinyl PE chains and is commensurate with the $\omega$ -
Subsequently, large excesses of AA (40 eq. and 60 eq.) were used

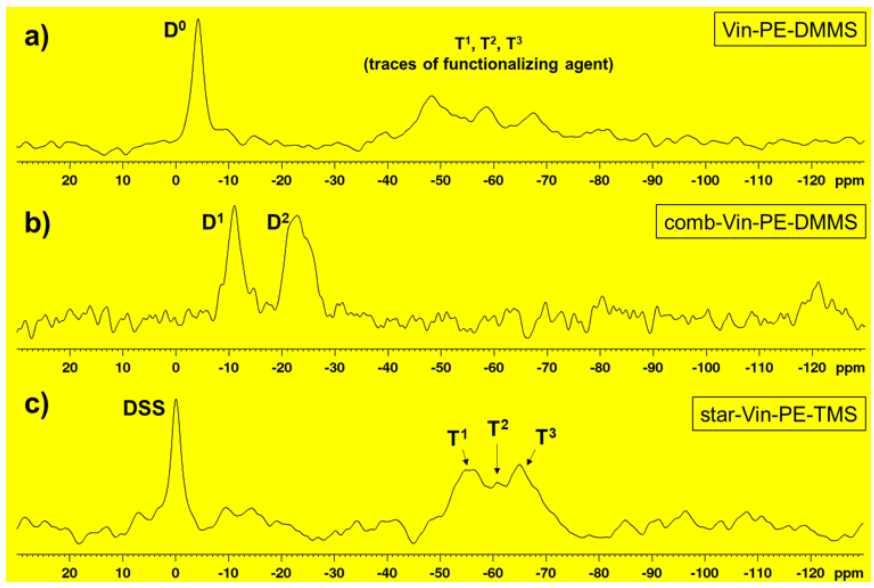

Figure $3 .{ }^{29} \mathrm{Si} \mathrm{NMR}$ (CP-MAS) spectra of a) Vin-PE-DMMS, b) comb-Vin-PE-DMMS and c) star-Vin-PE-TMS

for dimethoxyvinylsilyl- and trimethoxysilyl- functionalized PE, respectively (See corresponding ${ }^{1} \mathrm{H}$ NMR and HT-SEC analyses on Figure 2). The methoxy resonance in the corresponding polymers (at 3.38, 3.41 and 3.44 ppm in Vin-PE-DMMS, Vin-PE-DMVS and VinPE TMS, respectively) also disappears for star-Vin-PE-TMS, but residues for comb-Vin-PE-DMVS indicate that the acetoxylation/hydrolysis reaction is less favoured on a vinylsilyl group with about $4.8 \%$ of residual methoxysilyl group. In addition, the triplets of the methylene adjacent to the silicon atom (signal e in Figure 1) are at around $0.6 \mathrm{ppm}$ under the form of a broad signal, explained by a possible loss of mobility of the protons in $\alpha$ position with respect to the silicon atom. The ${ }^{13} \mathrm{C}$ NMR analyses also confirm the disappearance of the $-\mathrm{CH}_{2}-\mathrm{Si}$ signals (Figure S10, S11). Moreover, these analyses show broader and weaker signals which confirms the hypothesis of a loss of mobility in the close proximity of the polysiloxane main chain (Scheme 1). These specific signals in the ${ }^{13} \mathrm{C}$ NMR spectra are assigned at 17.8, 23.4, 28.9 and $33.5 \mathrm{ppm}$, in the case of comb-Vin-PE-DMMS and they are assigned at 12.69, $16.21,23.22$ and 33.54 for star-Vin-PE-TMS. They could be attributed to different condensation degrees of methoxysilyl groups, as well as different polyethylenic methylene groups in $\alpha-, \beta$ and $\gamma$ - positions of the Si center. ${ }^{1} \mathrm{H}-{ }^{13} \mathrm{C}$ HSQC spectra showed correlation between the broad signals in ${ }^{13} \mathrm{C}$ spectra at 12.69 and $16.21 \mathrm{ppm}$ and the broad signals in the ${ }^{1} \mathrm{H}$ NMR spectra around 0.6 ppm as shown for star-Vin-PE-TMS (Figure S12) confirming the formation of siloxane links and the hypothesis of different 
condensation degrees. To examine in depth the structures obtained after condensation, solid-state cross polarization magic angle spinning (CP-MAS) ${ }^{29} \mathrm{Si}$ NMR spectroscopy was additionally performed on comb-Vin-PE-DMMS, star-Vin-PE-TMS. The starting Vin-PE-DMMS was also analysed and the corresponding spectrum showed one singlet at $-4.25 \mathrm{ppm}$ (Figure 3a), corresponding to the $\omega$-alkoxysilyl group $-\underline{\mathrm{Si}}\left(\mathrm{CH}_{3}\right)\left(\mathrm{OCH}_{3}\right)_{2}\left(\mathrm{D}^{0}\right)$. Signals characteristic of partially condensed functionalizing agent (TMMS) were also identified in the $T$ regions around $-60 \mathrm{ppm}$, and may be due to insufficient washing steps in this particular sample. After condensation of Vin-PE-DMMS during 24 hours (Figure $3 \mathrm{~b}$ ), one can clearly observe the full disappearance of the $D^{0}$ signal and the appearance of signals corresponding to $\mathrm{D}^{1}\left(-\mathrm{Si}\left(\mathrm{CH}_{3}\right)(\mathrm{OH})(\mathrm{OSi})\right)$ at $-11.08 \mathrm{ppm}$ and $\mathrm{D}^{2}\left(-\underline{\mathrm{Si}}\left(\mathrm{CH}_{3}\right)(\mathrm{OSi})_{2}\right)$ at $-22.88 \mathrm{ppm}$ with at $43: 57$ molar ratio. As these NMR characterizations must be run for several hours under atmospheric conditions, rapid hydrolysis of Vin-PE-TMS does not allow proper characterization of this functional macromonomer. The spectrum of star-Vin-PE-TMS (Figure 3c) showed signals near $-56,-60$ and -65 ppm that are characteristic of $\mathrm{T}^{1}, \mathrm{~T}^{2}$ and $\mathrm{T}^{3}$ species, respectively. The $\mathrm{T}^{0}$ species are expected around $-40 \mathrm{ppm}$ and are barely discernible from the baseline noise. To summarize, where ${ }^{1} \mathrm{H}$ NMR analysis is useful to identify hydrolysis on the silicon atom, ${ }^{13} \mathrm{C}$ NMR and ${ }^{29} \mathrm{Si}$ NMR are more sensitive to the environment around the silicon atom and ${ }^{29} \mathrm{Si} N \mathrm{NM}$ can give quantitative information. HT-SEC analyses (Figure 2) are fully in line with the NMR analyses, and show the presence of noncondensed, low molar mass polyethylenes in all cases.

In the case of Vin-PE-DMMS, full hydrolysis, and conversion of methyldimethoxysilyl groups into $D^{1}$ and $D^{2}$ species indicates that the residual low molar mass species only consist in nonfunctionalized chains. The condensed polyethylenes display significantly higher molar masses which is consistent with a comblike structure.

In the case of star-Vin-PE-TMS, the HT-SEC and NMR analyses are also coherent with the full hydrolysis of the methoxysilyl groups and a significant condensation degree. Given the higher functionality of the TMS end-groups, the increase of molar masses is even larger than for comb-Vin-PE-DMMS. Residual low molar mass is also observed, corresponding to non-functionalized chains and possibly hydrolyzed but non-condensed $\mathrm{T}^{0}$ species.

The dimethoxyvinylsilyl-functionalized PE showed the lowest reactivity of the three samples, with a hydrolysis rate of $95 \%$ and a lesser degree of condensation as demonstrated by the reduced shift in the HT-SEC chromatogram. ${ }^{49}$

In order to confirm the differences in chain conformation of the functional polyethylenes upon condensation, Mark-Houwink plots of the intrinsic viscosity as a function of the molecular weights were represented in Figure S13. In this classical model, $[\boldsymbol{\eta}]=\mathbf{K M}^{\alpha}$, the value of the $\alpha$-parameter is characteristic of the conformation of the chains in dilute solution. ${ }^{50} \mathrm{~A}$ dramatic decrease of the $\alpha$ parameter is observed upon condensation for Vin-PE-DMMS, i.e. from $\alpha=1.17$ to $\alpha=0.11$ and for Vin-PE-TMS, i.e. from $\alpha=0.89$ to $\alpha$ $=0.14$. In both cases, these changes indicate a transition of conformation from linear coils in good solvent to much denser, hard sphere-like conformations. These results are in excellent accordance with $\alpha$-parameters reported for star-shaped polymers (e.g. in the 0.25-0.01 range). ${ }^{32,33}$ Regarding the comb-like polymers, it has been reported that very high molar mass and highly dense comb polymers behaving as "bottle-brushes" should display $\alpha$ parameters similar to linear coils. However, combs with molar masses lower than $10 \mathrm{kD}$ should rather behave as hyper-branched or star-like polymers, thus displaying low $\alpha$-parameters. ${ }^{51,52}$ The latter case corresponds well to the comb-Vin-PE-DMMS sample.

We recently demonstrated in the case of less sophisticated $\alpha, \omega$ divinyl polyethylenes that a segmented reactive approach, consisting in coupling or cross-linking end-functional polyethylene segments of well-defined length, enabled to combine very effectively crystallinity and cross-link density. The high potential of such materials was illustrated by the formation of highly resilient, shape-memory polyethylene aerogels. ${ }^{53}$ While the segmented approach has been extensively used in other polymers such as polyurethanes, only recent synthetic developments have made it available for polyethylene as ROMP followed by hydrogenation, ${ }^{54}$ depolymerization via $\mathrm{ADMET},{ }^{55}$ chain doubling of monounsaturated fatty acids, ${ }^{56,57}$ and CCG. ${ }^{37,58,59}$ The two-steps synthetic strategy that we have developed in this paper enables to obtain polyethylenebased architectures with well-defined lengths of polyethylene segments, and, most importantly, with high vinyl- end-group functionalities, , $\boldsymbol{f} \approx \mathbf{5}$, for comb-Vin-PE-DMMS and star-Vin-PETMS, and vinyl- and vinylsilyl- end-groups for comb-Vin-PE-DMVS attaining a total functionality of $\boldsymbol{f} \approx \mathbf{4}$. The large potential of such materials is demonstrated by the thermal properties of the postcondensed samples (Table 1), with melting temperatures remaining in the $115-120{ }^{\circ} \mathrm{C}$ range upon condensation, and crystallinities remaining above $50 \%$, even for comb-Vin-PE-DMMS, i.e. the sample with the highest extent of reaction of methoxysilyl groups according to ${ }^{29}$ Si NMR and HT-SEC chromatograms.

\section{Conclusions}

In conclusion, vinyl functionalized PE chains produced by catalyzed polyethylene chain growth were functionalized in situ after polymerization using trimethoxymethylsilane (TMMS) tetramethoxysilane (TMOS) and trimethoxyvinylsilane (TMVS). to form hetero-telechelic $\alpha$-vinyl, $\omega$-alkoxysilyl PEs (Vin-PE-DMMS, Vin-PE-DMVS and Vin-PE-TMS, respectively) in one pot. Characterizations of the formed hetero-telechelic $\alpha$ vinyl, $\omega$-methoxysilyl by ${ }^{1} \mathrm{H},{ }^{13} \mathrm{C},{ }^{29} \mathrm{Si}$ (CP-MAS) NMR spectroscopies, MALDI-TOF MS and HT SEC showed that the expected structures were obtained with functionalization rates higher than $80 \%$. A simple treatment of these polymers in acidic medium, leads to the condensation of alkoxysilyl group. Although different condensation degrees are observed during this last step, this chemistry gives access to either brush-like or star-like architectures retaining vinyl functionality and crystallinity provided by the starting PE building blocks. These simple strategies provide thus an easy access to functional PE architectures that could be further utilized for polyolefinbased materials. 


\section{Conflicts of interest}

There are no conflicts to declare.

\section{Acknowledgements}

We thank ANR for financial support (grant AEROLEFIN, ANR17-CE07-0006), the SEC characterization platform of Lyon Polymer Science and Engineering and the NMR-polymer characterization platform at Lyon Institute of Chemistry. We thank Frédéric Delolme for MALDI-TOF characterization.

\section{Notes and references}

1 Handbook of Adhesion Technology, ed. L. F. M. Da Silva, A. Öchsner and R. D. Adams, 2011

2 Handbook of Sealant Technology, ed. K. L. Mittal and A. Pizzi, CRC Press, Boca Raton, FL, 2009

3 Adhesive Technology Handbook, ed. S. Ebnesajjad, 2008, ch. 1, pp. 1-19

4 S. M. Guillaume, Polym. Chem., 2018, 9, 1911-1926

5 K. R. Brzezinska, K. B. Wagener and G. T. S Burns, J. Polym Sci. Part A Polym. Chem., 1999, 37, 849-856

6 S. Hilf and A. F. M. Kilbinger, Nat. Chem., 2009, 1, 537-546

7 X. Michel, S. Fouquay, G. Michaud, F. Simon, JM. Brusson, P. Roquefort, T. Aubry, JF. Carpentier and S. M. Guillaume, Polym. Chem., 2017, 8, 1177-1187

8 D. Derouet, S. Forgeard and J.-C. Brosse, Macromol. Chem. Phys., 1998, 199, 1835-1842

9 D. Derouet, S. Forgeard and J.-C. Brosse, Macromol. Chem Phys., 1999, 200, 10-24

10 J. S. Lee, A. Hirao and S. Nakahama, Macromolecules, 1988 21, 274-276

11 L. Emery, D. Buzare, Derouet, S. Forgeard and J.-C. Brosse, J. A, J. Polym. Sci. Part A Polym. Chem., 1997, 437-453

12 W. E. Lindsell, K. Radha and I. Soutar, Polym. Int., 1991, 25 1-6

13 R.P. Quirk, TH. Cheong, K. Jiang, D.L. Gomochak, T. Yoo, K. T. Andes and R. T. Mathers, Macromol. Symp., 2003, 195, 6974

14 K. Viswanathan, T. E. Long and T. C. Ward, J. Polym. Sci. Part A Polym. Chem., 2005, 43, 3655-3666

15 J. Hyun, Y. Kimura and H. Yamane, Macromol. Mater. Eng., 2015, 300, 1123-1132

16 V. Senkovskyy, R. Tkachov, T. Beryozkina, H. Komber, U. Oertel, M. Horecha, V. Bocharova, M. Stamm, S. A. Gevorgyan, F. C. Krebs and A. Kiriy, J. Am. Chem. Soc., 2009, 131, 16445-16453

17 P. Boufflet, A. Casey, Y. Xia, P. N. Stavrinou and M. Heeney, Chem. Sci., 2017, 8, 2215-2225

18 F. Schapman, J. P. Couvercelle and C. Bunel, Polymer, 1998, 39, 965-971

19 F. Schapman, J. P. Couvercelle and C. Bunel, Polymer, 1998, 39, 973-979

20 F. Schapman, J. P. Couvercelle and C. Bunel, Polymer, 1998, 39, 4955-4962

21 F. Schapman, J. P. Couvercelle and C. Bunel, Polymer, 2000, 41, 17-25

22 H. Kaddami, F. Surivet, J. F. Gérard, T. M. Lam and J. P. Pascault, J. Inorg. Organomet. Polym., 1994, 4, 183-198

23 F. Surivet, T. M. Lam, J. P. Pascault and C. Mai, Macromolecules., 1992, 25, 5742-5751

24 P. Liu, L. He, H. Ding, J. Liu and X. Yi, J. Appl. Polym. Sci., 2005, 97, 611-619
25 Z. Yang, H. Peng, W. Wang and T. Liu, J. Appl. Polym. Sci., 2008, 109, 1105-1113

26 T. Okamatsu and M. Ochi, Polymer, 2001, 43, 721-730

27 M. Van de Velde and E. J. Goethals, Makromol. Chem., Makromol. Symp., 1986, 6, 271-276

28 D. Ravaine, A. Seminel, Y. Charbouillot and M. Vincens, J. Non. Cryst. Solids., 1986, 82, 210-219

29 F. Surivet, T. M. Lam, J. P. Pascault and Q. T. Pham, Macromolecules, 1992, 25, 4309-4320

30 H. H. Huang and G. L. Wilkes, Polym. Bull., 1987, 18, 455-462

31 S. Subramani, J. M. Lee, I. W. Cheong and J. H. Kim, J. Appl. Polym. Sci., 2005, 98, 620-631

32 Y. Zhang, H. Li, Z. Xu, W. Bu, C. Liu, JY. Dong and Y. Hu, Polym. Chem., 2014, 5, 3963-3967

33 Z. Peng, D. Yi, Z. Xue, H. Li, Q. Li and Y. Hu, Macromol. Chem. Phys., 2017, 218, 1700143

34 Y. Zhang, H. Li, Q. Li and Y. Hu, Polym. Chem., 2014, 5, 105115

35 Z. Dong and Z. Ye, Polym. Chem., 2012, 3, 286-301

36 Z. Ye, L. Xu, Z. Dong and P. Xiang, Chem. Commun., 2013, 49 6235-6255

37 I. German, W. Kelhifi, S. Norsic, C. Boisson and F. D'Agosto, Angew. Chemie Int. Ed., 2013, 52, 3438-3441

38 W. Nzahou Ottou, S. Norsic, I. Belaid, C. Boisson and F. D'Agosto, Macromolecules, 2017, 50, 8372-8377

39 R. Briquel, J. Mazzolini, T. Le Bris, O. Boyron, F. Boisson, F. Delolme, F. D'Agosto, C. Boisson and R. Spitz, Angew. Chem. Int. Ed., 2008, 47, $9311-9313$

40 J. Mazzolini, E. Espinosa, F. D’Agosto and C. Boisson, Polym. Chem., 2010, 1, 793-800.

41 J. Mazzolini, I. Mokthari, R. Briquel, O. Boyron, F. Delolme, V. Monteil, D. Bertin, D. Gigmes, F. D'Agosto and C. Boisson, Macromolecules, 2010, 43, 7495-7503

42 J. Lacombe, S. Pearson, F. Pirolt, S. Norsic, F. D'Agosto, C. Boisson and C. Soulié-Ziakovic, Macromolecules, 2018, 51, 2630-2640

43 S. Norsic, C. Thomas, F. D'Agosto and C.Boisson, Angew. Chemie Int. Ed., 2015, 54, 4631-4635

44 J. Cervantes, R. Zárraga and C. Salazar-Hernández, Appl. Organomet. Chem., 2012, 26, 157-163

45 A. Kalinina, N. Strizhiver, N. Vasilenko, N. Perov, N. Demchenko and A. Muzafarov, Silicon, 2015, 7, 95-106

46 E. V. Egorova, N. G. Vasilenko, N. V. Demchenko and A. M. Muzafarov, Dokl. Chem., 2009, 424, 15-18

47 R. Ribeiro, R. Ruivo, H. Nsiri, S. Norsic, F. D'Agosto, L. Perrin and C. Boisson, ACS Catal., 2016, 6, 851-860

48 B. H. Staudt, J. Wagner and P. Vana, Macromolecules, 2018 , 51, 8469-8476

49 M. C. Brochier Salon and M. N. Belgacem, Phosphorus, Sulfur Silicon Relat. Elem., 2011, 186, 240-254

50 H. Mark, Der Feste Körper, Hirzel, Leipzig, 1938

51 K. Terao, T. Hokajo, Y. Nakamura and T. Norisuye, Macromolecules, 1999, 32, 3690-3694

52 S. Dutta, M. A. Wade, D. J. Walsh, D. Guironnet, S. A. Rogers and C. E. Sing, Soft Matter, 2019, 15, 2928-2941

53 D. Khedaioui, C. Boisson, F. D'Agosto and D. Montarnal, Angew. Chem. Int. Ed., 2019, 58, 15883-15889

54 A. D. Todd, R. J. McEeany, V. A. Topolkaraev, C. W. Macosko and M. A. Hillmyer, Macromolecules, 2016, 49, 8988-8994

55 V. B. Patil, K. O. Saliu, R. M. Jenkins, E. M. Carnahan, E. J. Kramer, G. H. Fredrickson and G. C. Bazan, Macromol. Chem. Phys., 2014, 215, 1140-1145

56 T. Witt, M. Häußler, Stefanie Kulpa and S. Mecking, Angew. Chemie Int. Ed., 2017, 56, 7589-7594

57 L. Yan, M. Häußler, J. Bauer, S. Mecking and K. I. Winey, Macromolecules, 2019, 52, 4949-4956 
58 H. Makio, T. Ochiai, J. Mohri, K. Takeda, T. Shimazaki, Y. Usui, S. Matsuura and T. Fujita, J. Am. Chem. Soc., 2013, 135, 8177-8180

59 S. S. Park, C. S. Kim, S. D. Kim, S. J. Kwon, H. M. Lee, T. H. Kim, J. Y. Jeon and B. Y. Lee, Macromolecules, 2017, 50, 6606-6616 